\begin{tabular}{|c|l|}
\hline Title & Modul able cooperativity in a val ence tautomeric complex functional ized with branched al kyl chains \\
\hline Author(s) & Kiriya, Daisuke; Nakamura, Kohei; Kitagawa, Susumu; Chang, Ho-Chol \\
\hline Citation & $\begin{array}{l}\text { Chemical Communications, 46(21), 3729-3731 } \\
\text { https://doi.org/40.1039/c001568g }\end{array}$ \\
\hline Issue Date & $2010-06-07$ \\
\hline Doc URL & http://hdl.handle.net/2115/45601 \\
\hline Rights & Chem. Commun., 2010, 46, 3729-3731- Reproduced by permission of The Royal Society of Chemistry (RSC) \\
\hline Type & article (author version) \\
\hline File Information & Cc46-21_3729-3731.pdf \\
\hline
\end{tabular}

Instructions for use 


\title{
Modulable Cooperativity in a Valence Tautomeric Complex Functionalized with Branched Alkyl Chains $\dagger$
}

\author{
Daisuke Kiriya, $\ddagger^{a}$ Kohei Nakamura $^{a}$, Susumu Kitagawa ${ }^{a}$ and Ho-Chol Chang ${ }^{* b}$ \\ Received (in $X X X, X X X)$ Xth $X X X X X X X X X 200 X$, Accepted Xth $X X X X X X X X X 200 X$ \\ ${ }_{5}$ First published on the web Xth $X X X X X X X X X 200 X$ \\ DOI: 10.1039/b000000x
}

Functionalization of a cobalt/dioxolene complex with branched, asymmetric alkyl chains promotes non-cooperative and cooperative valence tautomerisms synchronized with 10 thermodynamically favoured crystal-to-melt and kinetically generated glass-to-melt phase transitions, respectively, depending on the degree of crystallinity.

Bistable molecules such as spin crossover, thermochromic, and valence tautomeric (VT) complexes have been studied 15 extensively because of their intriguing changes in physical properties. $^{1-3}$ Synthetic challenges in the past few decades have been focused upon the introduction of cooperativity into these bistable regimes via supramolecular approaches. ${ }^{1,2,4}$ The introduction of effective intermolecular interactions such 20 as coordination bond, hydrogen bond, and/or $\pi$-stacking, enhances cooperativity, resulting in increased abruptness, wide hysteresis width, and large ON/OFF signal ratio in bistable transformations. $^{2,4,5}$ Moreover, further enhancement of cooperativity coexisting with structural flexibility results in 25 macroscopic phase transformations such as solid-solid, ${ }^{6,7}$ solid-liquid crystal $^{8}$ or liquid crystal-melt ${ }^{9}$ transitions synchronized with the molecular bistabilities. Changes in macroscopic properties, such as viscosity, reflectance, and dielectric polarization derived from assembed molecules 30 would turn these materials into a practical reality because macroscopic signals could be readily detectable, in contrast to inherently weak physicochemical signals from individual molecules. ${ }^{10}$ As demonstrated in the above results, the extent of coupling between molecular and macroscopic 35 transformations can be controlled by cooperativity. Therefore, it is crucial and challenging to design a molecular assembly having modulable cooperativity under controlled conditions. However, in a practical sense, cooperativity is hardly modulated in a given material when robust intermolecular 40 interactions are incorporated.

Our ongoing investigations of bistable VT complexes have Scheme 1. Schematic representation of VT interconversion of CoC8,10Opy.
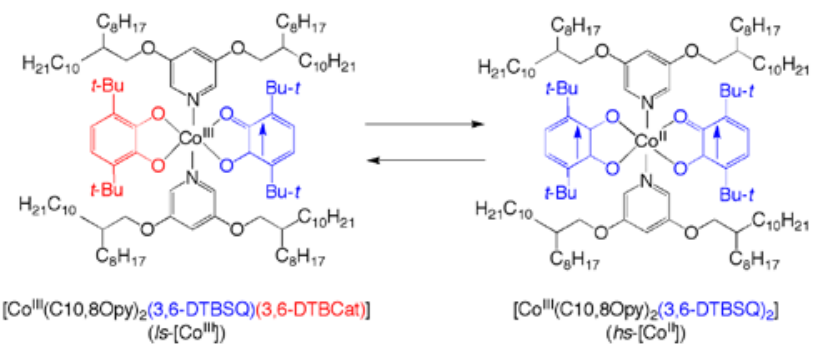

shown that complexes functionalized with alkyl chains demonstrate marked examples of synchronous interconversion of a molecular VT bistability and a macroscopic phase. ${ }^{6,11}$ 45 The observed cooperativity is derived in part from the nature of the linear alkyl chains, which show relatively high crystallinity. In contrast, a key strategy toward bistable materials with modulable cooperativity would require modulable intermolecular interactions. In this context, a new 50 VT complex with branched alkyl chains was designed and synthesized as shown in Scheme 1 . The effects of the branched, asymmetric alkyl chains will be demonstrated together with their kinetically controllable crystallization processes. $^{12}$

55 A new VT complex containing branched alkyl chain moieties was synthesized by mixing $\mathrm{Co}_{2}(\mathrm{CO})_{8}$, 3,6-di-tertbutyl-benzoquinone, and 3,5-bis(3-octyltridecyloxy)pyridine (C8,10Opy) in toluene. The reaction led to formation of a

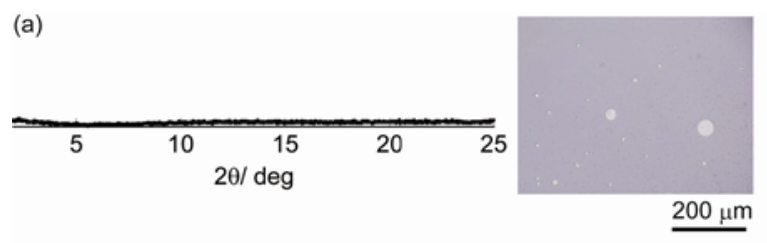

(b)

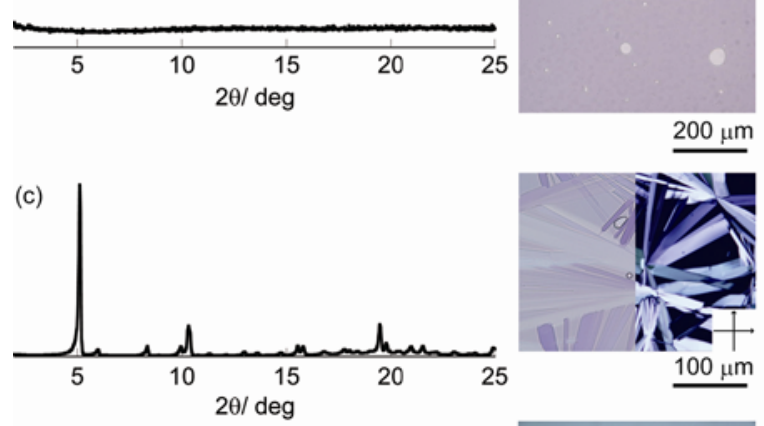

(d)

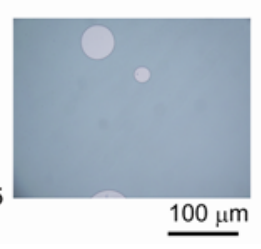

Figure 1. XRD patterns and microphotographs for CoC8,10Opy: (a) assynthesized oil (XRD at $298 \mathrm{~K}$, microphotograph at $275 \mathrm{~K}$ ), (b) glass phase (XRD at $190 \mathrm{~K}$, microphotograph at $193 \mathrm{~K}$ ), (c) crystalline phase obtained after holding the temperature at $295 \mathrm{~K}$ for $480 \mathrm{~min}$ (XRD at 296 K, microphotograph at $295 \mathrm{~K}$ (left: under parallel Nicole prisms, right: under crossed Nicole prisms), (d) melt (XRD at $314 \mathrm{~K}$, microphotograph at $373 \mathrm{~K})$. 
dark blue-purple solution from which $\left[\mathrm{Co}(\mathrm{C} 8,10 \mathrm{Opy})_{2}(3,6-\right.$ DTBQ $)_{2}$ ] (CoC8,100py in Scheme 1; 3,6-DTBQ $=3,6$-ditert-butyl-semiquinonate (3,6-DTBSQ) or -catecholate (3,6DTBCat)) was obtained as a purple oil, as shown in Figure 1a. 5 The as-synthesized oil shows no peaks in the X-ray diffraction (XRD) pattern and its fluidity indicates a melted state even at room temperature.

The as-synthesized oil shows $\chi_{\mathrm{M}} T$ values characteristic for the [low spin-Co ${ }^{\mathrm{III}}(\mathrm{C} 8,10 \mathrm{Opy})_{2}$ (3,6-DTBSQ)(3,6-DTBCat)] ${ }_{10}\left(l s-\left[\mathrm{Co}^{\mathrm{III}}\right]\right)$ tautomer at room temperature (Figure 2a). The temperature-dependent magnetic susceptibility of the oil shows a gradual increase in the $\chi_{\mathrm{M}} T$ values as the temperature was increased, indicating the formation of the [high spin$\left.\mathrm{Co}^{\mathrm{II}}(\mathrm{C} 8,10 \mathrm{Opy})_{2}(3,6-\mathrm{DTBSQ})_{2}\right]$ ( $\left.h s-\left[\mathrm{Co}^{\mathrm{II}}\right]\right)$ tautomer. In the 15 course of successive cooling, the $\chi_{\mathrm{M}} T$ values gradually decreased as the temperature was lowered and with a further second heating, a temperature dependence similar to the first heating process was observed (Figure 2a).§ The above results indicate a reversible VT equilibrium shift between the $l s$ $20\left[\mathrm{Co}^{\mathrm{III}}\right]$ and the $h s-\left[\mathrm{Co}^{\mathrm{II}}\right]$ tautomers. To reveal the detailed thermal events, differential scanning calorimetric (DSC) and XRD measurements were conducted. During both the heating and cooling processes, unexpected baseline anomalies were found at approximately $230 \mathrm{~K}$ in the DSC profile (Figure $2 \mathrm{~b}$ ). 25 In addition, an XRD pattern of the as-synthesized oil showed no peaks at $190 \mathrm{~K}$ and a microphotograph at around this temperature indicated an optically isotropic phase (Figure 1b). Therefore, the thermal anomalies in the DSC are attributable to the glass transition of CoC8,10Opy. As the above results so show, CoC8,10Opy exhibits a non-cooperative VT equilibrium between the $l s-\left[\mathrm{Co}^{\mathrm{III}}\right]$ and the $h s-\left[\mathrm{Co}^{\mathrm{II}}\right]$ tautomers over the melt and glass phases.

Interestingly, a crystalline phase was generated when the melt obtained from the glass by heating was kept at room 35 temperature for $480 \mathrm{~min}$ (Figure 1c and supplementary
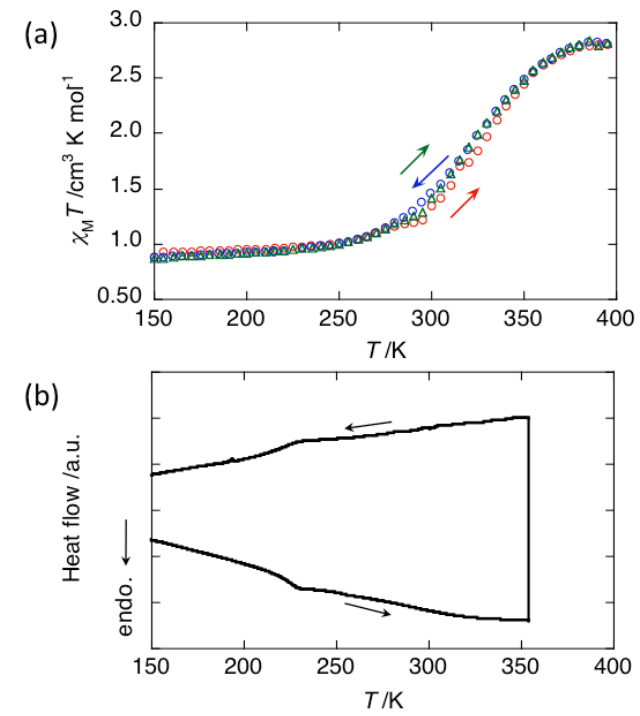

Figure 2. (a) Temperature-dependent magnetic susceptibility for the assynthesized sample of CoC8,10Opy on the first heating (red circles), cooling (blue circles) and second heating (green triangles) processes and (b) DSC curves observed for the first heating and cooling processes at a scan rate of $10 \mathrm{~K} \mathrm{~min}^{-1}$.

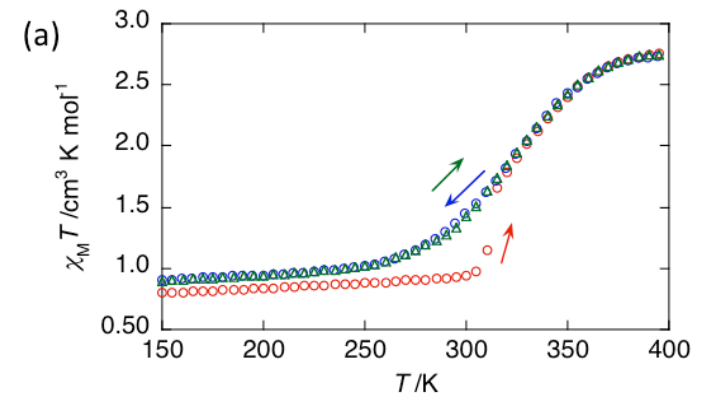

(b)

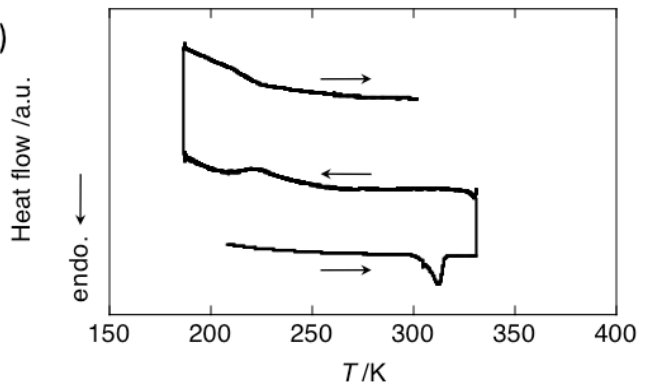

Figure 3. (a) Plots of the temperature-dependent magnetic susceptibility for the crystalline phase of CoC8,10Opy on the first heating (red circles), first cooling (blue circles) and second heating (green triangles) processes. (b) DSC curves measured for the crystalline phase in the first heating, first cooling and second heating processes at a scan rate of $1 \mathrm{~K} \mathrm{~min}^{-1}$.

information). $f$ The thermal behavior of the crystalline phase was shown in Figure 3. On heating the crystal showed a sharp endothermic peak at $T_{\mathrm{c}}=313 \mathrm{~K}\left(\Delta H_{\mathrm{c}}=50.3 \mathrm{~kJ} \mathrm{~mol}^{-1}\right.$ and $\Delta S_{\mathrm{c}}$ $=161 \mathrm{~J} \mathrm{~mol}^{-1} \mathrm{~K}^{-1}$ ) at a scan rate of $1 \mathrm{~K} \mathrm{~min}^{-1}$ (Figure 3b). In 40 addition, temperature dependent XRD experiments showed that the sharp XRD pattern of the crystal completely disappeared at $T_{\mathrm{c}}$ to give a featureless XRD pattern on heating (Figure 1d), undoubtedly demonstrating a crystal-melt phase transition. Furthermore, microphotographs visually ${ }_{45}$ demonstrated that the purple crystal (Figure 1c) transformed into an optically isotropic green melt with high fluidity at $T_{\mathrm{c}}$ (Figure 1d). The temperature-dependent magnetic susceptibility of the crystal demonstrated an abrupt increase from 0.97 to $1.67 \mathrm{~cm}^{3} \mathrm{~K} \mathrm{~mol}^{-1}$ at $312 \mathrm{~K}$ on heating as shown 50 in Figure 3a. This behavior can be understood as a cooperative VT interconversion from the $l s-\left[\mathrm{Co}^{\mathrm{III}}\right]$ to the $h s$ $\left[\mathrm{Co}^{\mathrm{II}}\right]$ tautomer during the heating process. As a result, the crystal of CoC8,10Opy shows a synchronous molecular VT and macroscopic crystal-melt phase transition. The observed 55 incomplete jump in the magnetic susceptibility is due to a small negative enthalpy effect derived from weak packing forces and a high positive entropy effect of the branched alkyl chains compared with those of linear alkyl chains. ${ }^{11}$ These effects result in decreasing the melting temperature, thereby 60 the $l s-\left[\mathrm{Co}^{\mathrm{III}}\right]$ and the $h s-\left[\mathrm{Co}^{\mathrm{II}}\right]$ tautomers are still in equilibrium in the melt.

Further heating of the melt leads to a gradual increase in the $\chi_{\mathrm{M}} T$ values, indicating the formation of the $h s-\left[\mathrm{Co}^{\mathrm{II}}\right]$ tautomer in the molten state (Figure 3a). On further 65 decreasing and increasing the temperature, thermal anomalies at approximately $230 \mathrm{~K}$ in the DSC profile (Figure $3 \mathrm{~b}$ ) and gradual changes in magnetic susceptibilities were observed again as for the thermal processes starting with as-synthesized 
oil (Figure 3a). As shown above, once the crystal melts, the melt and glass phases are reversibly interconverted under a scan rate of $1 \mathrm{~K} \mathrm{~min}^{-1}$. This behavior is due to kinetically hindered crystallization processes of CoC8,10Opy with the 5 branched alkyl chains. 1 As a whole, it was concluded that the non-cooperative and cooperative molecular bistabilities can be switched by thermal processes on CoC8,100py. The present modulation of cooperativity in a given pair of VT tautomers would give more chance to establish further advanced bistable 10 molecular materials, which can be used in future applications .

In summary, a VT complex with branched chains, CoC8,10Opy was synthesized and demonstrated noncooperative equilibrium shift over the glass and isotropic melting phases, while a cooperative VT interconversion over 15 the crystalline and melt phases was observed under the controlled kinetic factors.

This work was financially supported in part by a Grand-inAid for Scientific Research for Priority Area "Coordination Programming” (Area No. 2107) and the Global COE Program 20 (Project No. B01) from the Ministry of Education, Culture, Sports, Science and Technology, Japan.

\section{Notes and references}

${ }^{a}$ Department of Synthetic Chemistry and Biological Chemistry, Graduate School of Engineering, Kyoto University, Katsura, Nishikyo-ku, Kyoto

25 615-8510, Japan. Fax: +81-75-383-2732; Tel: +81-75-383-2733

${ }^{b}$ Division of Chemistry, Graduate School of Science, Hokkaido University, North 10 West 8, Kita-ku, Sapporo, 060-0810, Japan. Fax; +81-11-7063447; Tel: +81-11-706-3479; E-mail: chang@sci.hokudai.ac.jp

† Electronic Supplementary Information (ESI) available: [experimental 30 details, temperature dependent IR spectra, magnetic susceptibility data, crystallization process in SQUID magnetomater, temperature dependence of XRD patterns, and a movie of the crystallization process]. See DOI: $10.1039 / \mathrm{b} 000000 \mathrm{x} /$

¥ Current adress: Institute of Industrial Science (IIS), The University of 35 Tokyo 4-6-1 Komaba, Meguro-ku, Tokyo 153-8505, Japan.

$\S$ The observed VT equilibrium was also confirmed by using temperature-dependent IR spectroscopy, as shown in Figure S1.

f A XRD diffraction at $5.12 \AA$ corresponds to the interlayer distance, $17.2 \AA$ A $^{11}$

${ }_{40}$ - The melt obtained from the $h s-\left[\mathrm{Co}^{\mathrm{II}}\right]$ by cooling maintained the melting state for at least $480 \mathrm{~min}$ at room temperature (see supplementary information Figure S2).

1. P. Gütlich and H. A. Goodwin, Spin Crossover in Transition Metal

45 Compounds, Springer, Berlin, 2004.; J. A. Real, A. B. Gaspar, V. Niel and M. C. Munõz, Coord. Chem. Rev., 2003, 236, 121-141.

2. O. Kahn and C. J. Martinez, Science, 1998, 279, 44-48.

3. C. G. Pierpont, Coord. Chem. Rev., 2001, 216, 99-125; D. M. Adams, A. Dei, A. L. Rheingold and D. N. Hendrickson, J. Am. Chem. Soc.,

50 1993, 115, 8221-8229; S. Bin-Salamon, S. Brewer, S. Franzen, D. L. Feldheim, S. Lappi and D. A. Shultz, J. Am. Chem. Soc., 2005, 127, 5328-5329; G. J. Halder, C. J. Kepert, B. Moubaraki, K. S. Murray and J. D. Cashion, Science, 2002, 298, 1762-1765; S.-I. Ohkoshi, K. I. Arai, Y. Sato and K. Hashimoto, Nat. Mater., 2004, 3, 857-861; M.

55 Seredyuk, A. B. Gaspar, V. Ksenofontov, S. Reiman, Y. Galyametdinov, W. Haase, E. Rentschler and P. Gütlich, Chem. Mater., 2006, 18, 2513-2519; Y. Morita, S. Suzuki, K. Fukui, S. Nakazawa, H. Kitagawa, H. Kishida, H. Okamoto, A. Naito, A. Sekine, Y. Ohashi, M. Shiro, K. Sasaki, D. Shiomi, K. Sato, T. Takui
60 and K. Nakasuji, Nat. Mater., 2008, 7, 48-51; P. Gütlich and A. Dei, Angew. Chem. Int. Ed., 1997, 36, 2734-2736; M. E. Itkis, X. Chi, A. W. Cordes and R. C. Haddon, Science, 2002, 296, 1443-1445; M. Bartel, A. Absmeier, G. N. L. Jameson, F. Werner, K. Kato, M. Takata, R. Boca, M. Hasegawa, K. Mereiter, A. Caneschi and W. 65 Linert, Inorg. Chem., 2007, 46, 4220-4229; K. Kuroiwa, T. Shibata, A. Takada, N. Nemoto and N. Kimizuka, J. Am. Chem. Soc., 2004, 126, 2016-2021.

4. A. Bousseksou, G. Molnár and G. Matouzenko, Eur. J. Inorg. Chem., 2004, 4353-4369.

70 5. O. Kahn and J. P. Launay, Chemtronics, 1988, 3, 140-151; S. Hayami, Z. Gu, M. Shiro, Y. Einaga, A. Fujishima and O. Sato, J. Am. Chem. Soc., 2000, 122, 7126-7127; J. Kröber, E. Codjovi, O. Kahn, F. Grolière and C. Jay, J. Am. Chem. Soc., 1993, 115, 9810-9811; M. Yamada, H. Hagiwara, H. Torigoe, N. Matsumoto, M. Kojima, F. Dahan, J.-P. Tuchagues, N. Re and S. Iijima, Chem. Eur. J., 2006, 12, 4536 - 4549 .

6. D. Kiriya, H.-C. Chang, A. Kamata and S. Kitagawa, Dalton Trans., 2006, 1377-1382.

7. K. W. Törnroos, M. Hostettler, D. Chernyshov, B. Vangdal and H. B. 80 Bürgi, Chem. Eur. J., 2006, 12, 6207-6215; H. Tokoro, T. Matsuda, S. Miyashita, K. Hashimoto and S.-I. Ohkoshi, J. Phys. Soc. Jpn., 2006, 75, 08004/1-2; O.-S. Jung, D. H. Jo, Y.-A. Lee, B. J. Conklin and C. G. Pierpont, Inorg. Chem., 1997, 36, 19-24; E. Kōnig, G. Ritter, S. K. Kulshreshtha, J. Waigel and H. A. Goodwin, Inorg. Chem., 1984, 23, 1896-1902; P. Guionneau, J.-F. Létard, D. S. Yufit, D. Chasseau, G. Bravic, A. E. Goeta, J. A. K. Howard and O. Kahn, J. Mater. Chem., 1999, 9, 985-994.

8. S. Hayami, R. Moriyama, A. Shuto, Y. Maeda, K. Ohta and K. Inoue, Inorg. Chem., 2007, 46, 7692-7694; M. Seredyuk, A. B. Gaspar, V.

$90 \quad$ Ksenofontov, Y. Galyametdinov, J. Kusz and P. Gütlich, Adv. Funct. Mater., 2008, 18, 2089-2101; A. B. Gaspar, M. Seredyuk and R. Gütlich, Coord. Chem. Rev., 2009, 253, 2399-2413.

9. T. Fujigaya, D.-L. Jiang and T. Aida, J. Am. Chem. Soc., 2003, 125, 14690-14691.

95 10. B. Halford, Chem. Eng. News, 2007, 85, 34-35; M. Wuttig and N. Yamada, Nat. Mater., 2007, 6, 824-832; D. Demus, J. Goodby, G. W. Gray and H. W. Spiess, Handbook of Liquid Crystals, WILEY-VCH, Weinheim, 1998.

11. D. Kiriya, H.-C. Chang and S. Kitagawa, J. Am. Chem. Soc., 2008, 130, 5515-5522; D. Kiriya, H.-C. Chang, K. Nakamura, D. Tanaka, K. Yoneda and S. Kitagawa, Chem. Mater., 2009, 21, 1980-1988; D. Kiriya, K. Nakamura, H.-C. Chang and S. Kitagawa, Chem.Commun., 2009, 4085 - 4087.

12. W. Pisula, M. Kastler, D. Wasserfallen, M. Mondeshki, J. Piris, I. 105 Schnell and K. Müllen, Chem. Mater., 2006, 18 3634-3640; F. Nolde, W. Pisula, S. Muller, C. Kohl and K. Müllen, Chem. Mater., 2006, 18, 3715-3725. 